\title{
Mixed trichuroid infestation in a dog from Italy
}

\author{
Angela Di Cesare ${ }^{1}$, Giuseppe Castagna ${ }^{1}$, Silvana Meloni ${ }^{1}$, Domenico Otranto ${ }^{2}$ and Donato Traversa ${ }^{*}$
}

\begin{abstract}
Background: Capillaria aerophila, Capillaria boehmi and Trichuris vulpis are trichuroid nematodes affecting wild and companion animals all over the World. The canine intestinal whipworm, T. vulpis, is the most common and wellknown in veterinary practice, whereas the respiratory C. aerophila and C. boehmi have been rarely reported in pets as a likely consequence of overlapping morphometric and morphological features of the eggs, which impair a correct etiological diagnosis.

Findings: In December 2011, a mixed infestation by T. vulpis, C. aerophila and C. boehmi was diagnosed in an asymptomatic dog living in central Italy. Morphometric and morphological findings and pictures of the eggs found at the copromicroscopic analysis are herein reported.

Conclusions: The present work demonstrates that when trichuroid eggs are found in a faecal sample from a dog, a careful morphological and morphometric analysis of individual parasite elements is mandatory. Key diagnostic features (i.e., size, wall surface pattern and aspects of plugs) should be carefully examined when eggs with overlapping shape and appearance are detected. In conclusion, given the importance in clinical practice of canine trichuroids and the zoonotic potential of $C$. aerophila, these nematodes should be included into the differential diagnosis of intestinal and respiratory parasitoses of dogs by a thorough microscopic analysis of all trichuroid ova present in microscopic fields.
\end{abstract}

Keywords: Capillaria aerophila, Capillaria boehmi, Trichuris vulpis, Italy, Mixed infestation, Diagnosis

\section{Findings}

Background

Parasitic nematodes belonging to the family Trichuridae infest wild and domestic animals, and human beings as well. The so-called "canine whipworm" Trichuris vulpis is the most known and it affects the large bowel of dogs and wild canids. The life cycle of T. vulpis, which is direct and based on a soil-transmitted oral route of infestation via embryonated eggs, is well understood, albeit some biological aspects of this nematode (e.g., bloodsucking and zoonotic abilities) have yet to be elucidated [1]. Conversely, the respiratory nematode Capillaria aerophila is poorly known. Adult stages inhabit the epithelium of bronchioles, bronchi and trachea of foxes, badgers, raccoons, bears, dogs, cats and, occasionally, humans [2-4]. The life cycle of $C$. aerophila is direct and animals become infected by ingesting environmental embryonated eggs; earthworms can be implicated in the

\footnotetext{
* Correspondence: dtraversa@unite.it

'Department of Comparative Biomedical Sciences, University of Teramo,

Valenzano, Italy

Full list of author information is available at the end of the article
}

transmission of C. aerophila, although whether as facultative intermediate or paratenic hosts is yet to be understood [2,5]. A third species, Capillaria boehmi, lives in the nasal cavities and sinuses of wild canids (e.g., foxes and wolves) and domestic dogs, and its life cycle is unknown [6].

While the canine whipworm is a ubiquitous parasite infesting all categories of dogs (i.e. pets, kenneled and stray dogs), with high prevalence all over the World [1], C. aerophila and C. boehmi are commonly found in wildlife [6]. Nonetheless, in the last decade an increasing trend in the number of infestations in domestic animals has been recorded, being C. aerophila reported in dogs from Europe, North America and Australia (rev. in Traversa et al., 2010), and C. boehmi in dogs from Europe and North America [7-10]. Most infestations by canine whipworms in adult patients can be asymptomatic, although heavy parasitic burdens may induce colitis with different symptoms irrespective of the age of infected animals [1]. Animals harboring C. aerophila can be either asymptomatic or display different respiratory distresses with varying degree of severity $[2,11]$. Dogs 
infected with C. boehmi may be asymptomatic but, when symptoms occur, infected animals show upper respiratory tract signs $[12,13]$.

The diagnosis of these trichuroid infestations relies on the detection of the typical eggs through standard fecal floatations irrespective of the great morphological similarities of the ova, which pose important challenges in epidemiological and clinical settings.

This article reports the simultaneous occurrence of $T$. vulpis, C. aerophila and C. boehmi in a dog and presents key morphological characters for a reliable diagnosis at the species level.

\section{Methods}

In December 2011 a dog living in Latina Municipality (Lazio region, Central Italy) was clinically examined and subjected to a copromicroscopic analysis. A faecal sample collected from the rectum of the dog was examined at the Parasitology Laboratory of the Department of Comparative Biomedical Science of the University of Teramo using a standard floatation procedure incorporating a zinc sulphate solution with a specific gravity of 1.350 [14]. Briefly, about five grams of faeces were added to $20 \mathrm{ml}$ of floatation solution and then the mixture was strained through a double layer of cheesecloth. The solution was poured into a $15-\mathrm{ml}$ centrifuge tube and centrifuged at $1200 \mathrm{rpm}$ for five minutes. A pasteur pipette was then used to transfer a supernatant aliquot of $\sim 100 \mu \mathrm{l}$ to a glass slide, and the slide was examined using a light microscope (Axioscope 40, Zeiss, Oberkochen, Germany) at 200X and 400X magnifications [14].

Given that several trichuroid eggs (i.e. $\mathrm{n}=45$ ) with overlapping shape and appearance, but with slight differences, were detected, all parasitic elements found in the examined slide (coverslip of $24 \times 50 \mathrm{~mm}$ ) were undertaken and a thorough morphological and morphometric analysis were carried out.

\section{Results}

The dog presented no clinical signs and was apparently healthy. All eggs in the sample showed a lemon/barrellike appearance with two plugs at the extremities. However, the morphologic and morphometric examination, conducted using diagnostic keys (Table 1), showed the presence of three different trichuroids simultaneously affecting the dog, i.e. T. vulpis $(\mathrm{n}=27$ eggs), C. aerophila ( $\mathrm{n}=12$ eggs) and $C$. boehmi ( $\mathrm{n}=7$ eggs) (Figures $1,2,3)$.

Ova of $T$. vulpis were symmetrical, with ring-like thickening at the plug bases (Figure 4) and presented a brown color, smooth surface and a size ranging from $83.50 \pm 3.00 \mu \mathrm{m}$ in length and $36.00 \pm 3.50 \mu \mathrm{m}$ in width. Capillaria aerophila eggs were smaller than those of $T$. vulpis, i.e. lengths of major and minor axes were $64.45 \pm 1.50 \mu \mathrm{m}$ and $34.95 \pm 3.40 \mu \mathrm{m}$, respectively. Also, they showed asymmetrical bipolar plugs with no ring thickening (Figure 4) and a network of anastomosing ridges and bridges on their walls (Figure 5). Eggs of $C$. boehmi were morphologically kindred to those of $C$. aerophila, having asymmetry of no-ringed plugs (Figure 4) and being smaller than those of $T$. vulpis. However, these eggs were even smaller than those of $C$. aerophila, with a size of $55.30 \pm 1.30 \mu \mathrm{m}$ in length and $32.40 \pm 2.60 \mu \mathrm{m}$ in width, and presented a surface characterized by several tiny pits and a space between embryo and wall (Figure 5).

\section{Discussion and conclusions}

This study reports for the first time an infestation by three species of trichuroids in the same animal, thus indicating that besides the most commonly retrieved $T$. vulpis, also C. aerophila and C. boehmi may infect dogs simultaneously. Thus, a thorough and careful microscopic examination of trichuroid eggs in faeces of dogs is always mandatory when barrel-shaped or lemon-like eggs are found.

Although nematodes ranked within the Capillaria genus occur in several geographic areas $[4,6,10,11,15]$ these species are neglected as a likely effect of the drawbacks in copromicroscopical identification of their eggs, which are often misdiagnosed with those of T. vulpis [5]. Additionally, eggs of $C$. boehmi can be mistaken with those of $C$. aerophila. In fact, while lung capillariosis has been frequently reported in dogs in the past few years, this is not the case for canine nasal capillariosis. As an example, the presence of C. boehmi in Italy is rather anecdotal, with only one report published [8] and recent personal communications (Veronesi, 2010, Perrucci

Table 1 Differential features of eggs of Trichuris vulpis, Capillaria aerophila and Capillaria boehmi

\begin{tabular}{|c|c|c|c|c|c|c|}
\hline Nematode & Length $\mu \mathrm{m}$ & Width $\mu \mathrm{m}$ & Morphological features & Plugs & Shell & Reference \\
\hline $\begin{array}{l}\text { Trichuris } \\
\text { vulpis }\end{array}$ & $72-94$ & $31-42$ & $\begin{array}{l}\text { lemon-like shape, } \\
\text { brownish }\end{array}$ & $\begin{array}{l}\text { symmetrical } \\
\text { presence } \\
\text { of rings }\end{array}$ & $\begin{array}{l}\text { thick and smooth } \\
\text { wall }\end{array}$ & {$[1,5]$} \\
\hline $\begin{array}{l}\text { Capillaria } \\
\text { aerophila }\end{array}$ & $60-65$ & $25-40$ & $\begin{array}{l}\text { barrel-like shape, } \\
\text { zygote fills the egg }\end{array}$ & $\begin{array}{l}\text { asymmetrical } \\
\text { no rings }\end{array}$ & $\begin{array}{l}\text { striated outer shell with a network } \\
\text { of anastomosis ridges and bridges }\end{array}$ & {$[4,5]$} \\
\hline $\begin{array}{l}\text { Capillaria } \\
\text { boehmi }\end{array}$ & $50-60$ & $30-35$ & $\begin{array}{l}\text { barrel-like shape, clear to golden, space } \\
\text { between the embryo and the wall }\end{array}$ & $\begin{array}{l}\text { asymmetrical } \\
\text { no rings }\end{array}$ & $\begin{array}{l}\text { tiny pits on the surface } \\
\text { of the wall }\end{array}$ & {$[4,10]$} \\
\hline
\end{tabular}




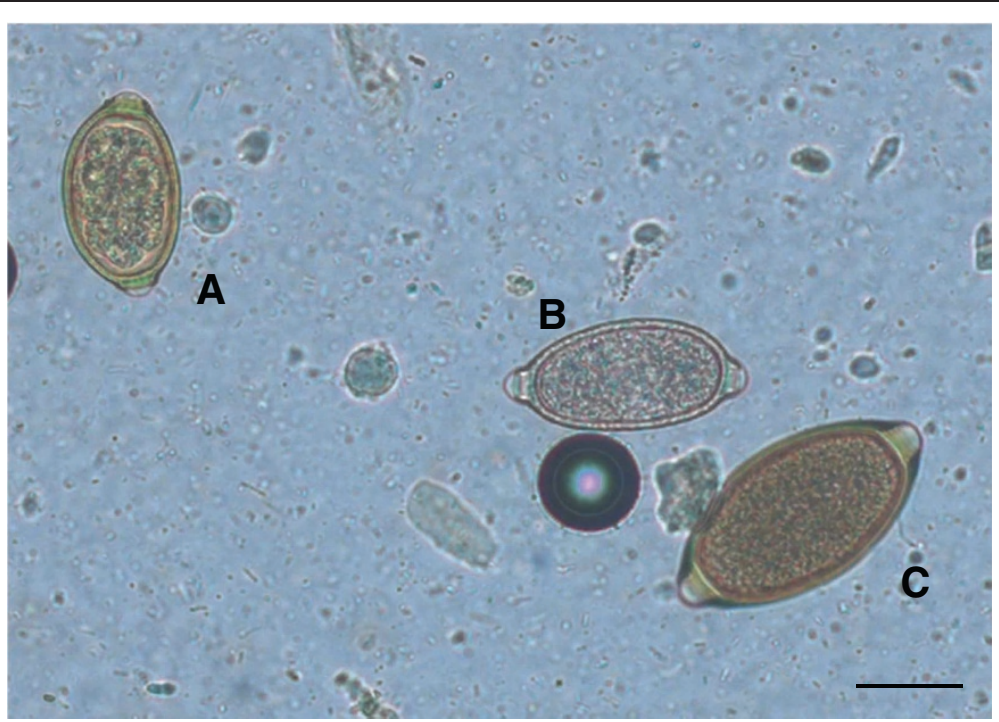

Figure 1 Eggs of Capillaria boehmi (A), Capillaria aerophila (B) and Trichuris vulpis (C) detected by light microscopy examination (200x magnification). Scale bar $=30 \mu \mathrm{m}$.

2012, pers. comm. to DT). The risk of misidentification is high and this is even more so in the presence of mixed infestations in which one species is more prevalent over the other/s, as in the case presented herein. In fact, if in the present report an analyst would have taken into account only more prevalent eggs without a careful examination of the whole microscopic field, the dogs would have been diagnosed only with a whipworm infestation.

An accurate appraisal of trichuroid eggs is of importance from a clinical standpoint. Dogs infected by T. vulpis may suffer from relevant systemic (e.g. reduced growth rate, wasting, weight loss, lethargy, anemia) and intestinal distresses (e.g. watery and haemorrhagic diarrhoea), which overlap a plethora of intestinal diseases with multiple etiology [1]. Also respiratory capillariosis induces aspecific symptoms, e.g. nasal discharge, sneezing, wheezing, chronic cough, dyspnea (C. aerophila) or sneezing, mucopurulent and/or bloody nasal scolum and anosmia (C. boehmi) $[4,5,9]$.

On the other hand, the presence of asymptomatic animals may be frequent $[1,4,8]$ and the lack of clinical signs in the dog herein examined confirms such evidence.

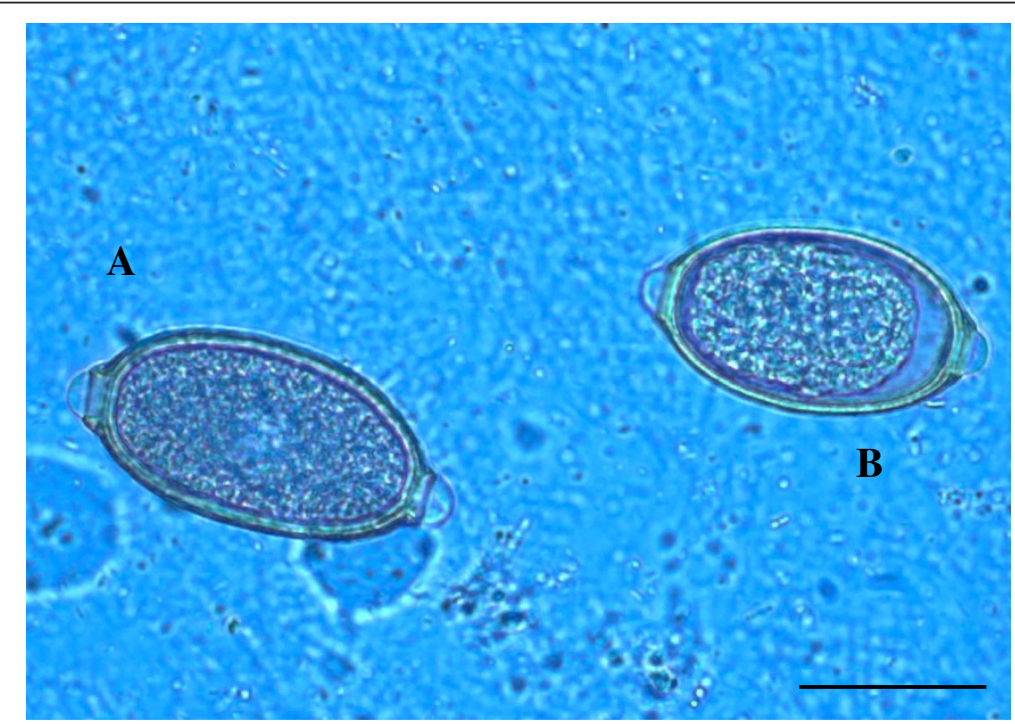

Figure 2 Eggs of Capillaria aerophila (A) and Capillaria boehmi (B) detected by light microscopy examination (400x magnification). Scale bar $=30 \mu \mathrm{m}$. 


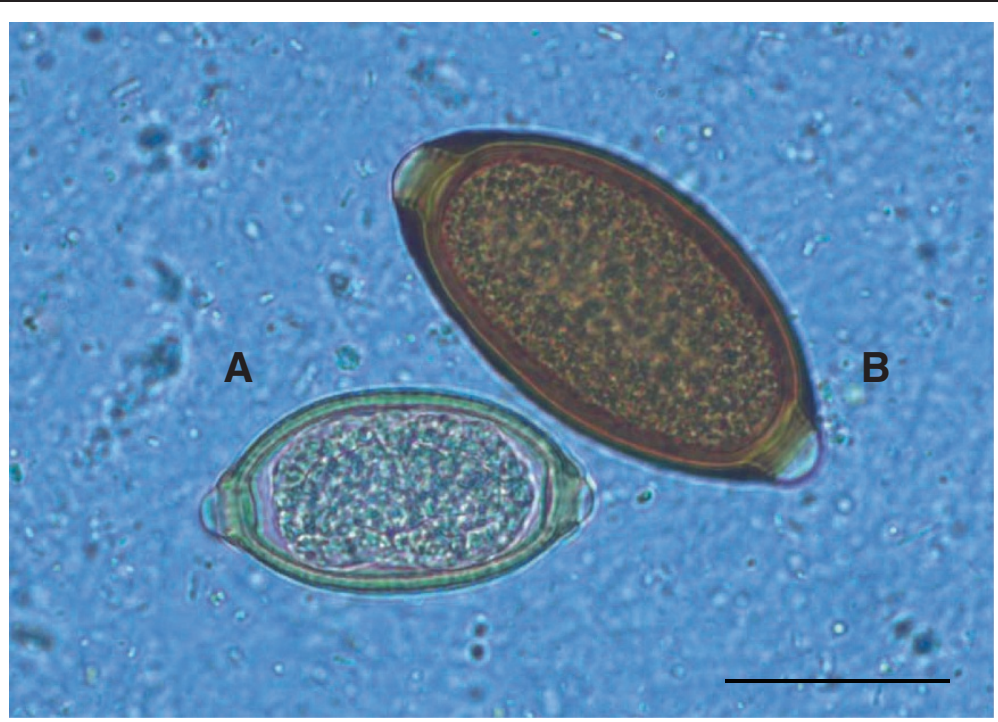

Figure 3 Eggs of Capillaria boehmi (A) and Trichuris vulpis (B) detected by light microscopy examination (400x magnification). Scale bar $=30 \mu \mathrm{m}$.

Hence, the lack of specificity of clinical signs or even the absence of symptoms in intestinal trichurosis and respiratory capillarioses, may complicate the work of veterinarians in diagnosing these parasitoses in pets.

A correct diagnosis of trichuroid infestations is pivotal considering a potential zoonotic role. In fact, while $C$. boehmi does not infest humans, the role of T. vulpis as a zoonotic agent is still controversial, and C. aerophila induces, although seldom, pulmonary capillariosis in people, causing fever, bronchitis, coughing, haemoptisis, dyspnoea and may mimic bronchial carcinoma $[1,3,4]$.

Further molecular studies are warranted to support a reliable identification of $T$. vulpis, C. aerophila and $C$. boehmi eggs in faecal samples. Recently, the efficiency of

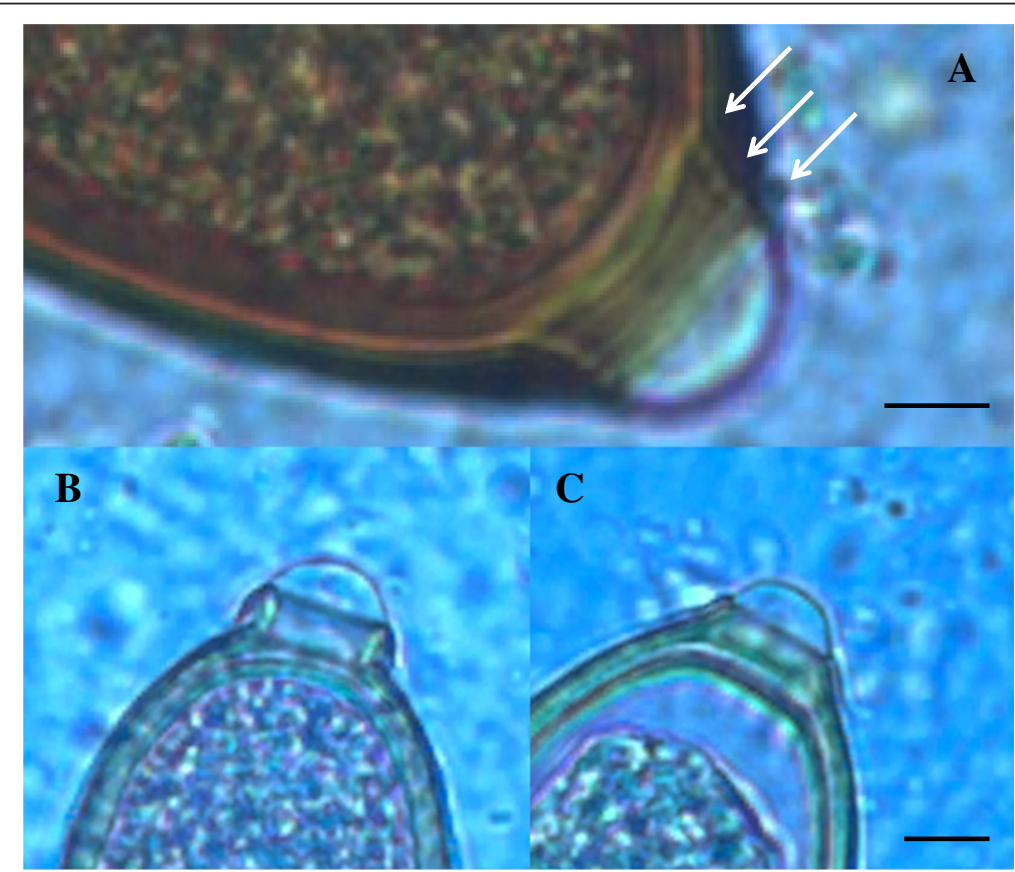

Figure 4 Egg polar plugs of Trichuris vulpis (A), Capillaria aerophila (B) and Capillaria boehmi (C). Arrows indicate thickening at the base of the bipolar plug of T. vulpis, which are absent in C. aerophila and C. boehmi. Scale bars $=5 \mu \mathrm{m}$. 


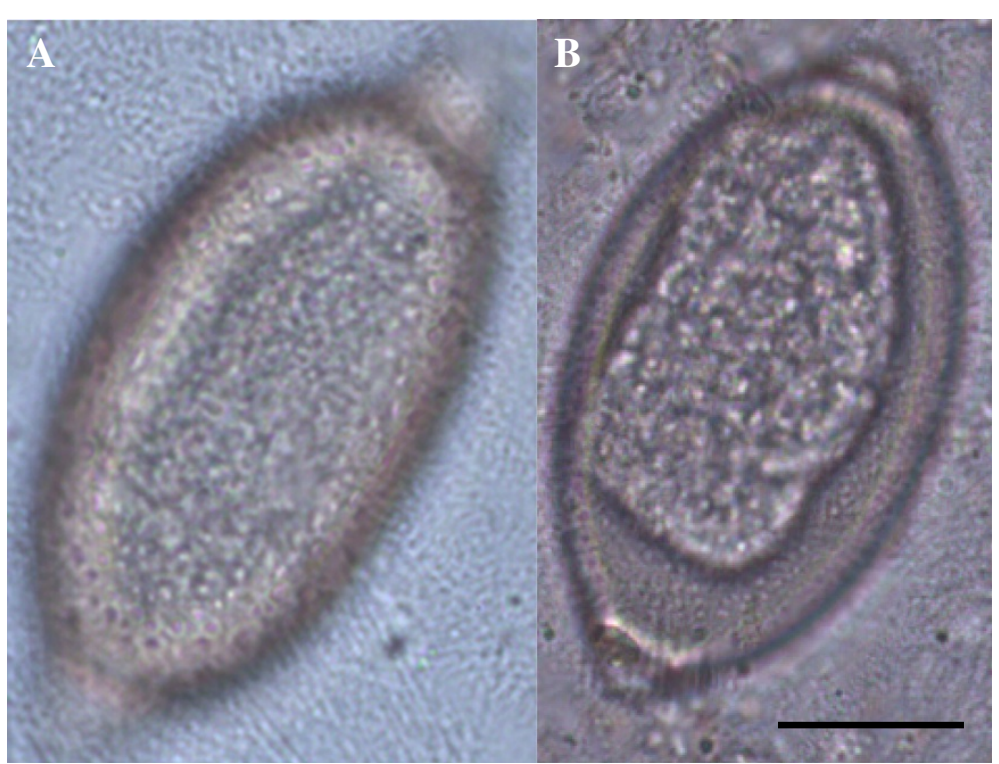

Figure 5 Outer shell of the egg of Capillaria aerophila (A) and Capillaria boehmi (B) showing the typical network of anastomosing ridges and bridges and the presence of tiny pits, respectively. Scale bar $=15 \mu \mathrm{m}$.

a mitochondrial DNA based assay in the diagnosis of lung capillariosis by C. aerophila has been demonstrated [16]. Similar studies are also presently ongoing for $T$. vulpis and C. boehmi, with the aim of validating a genetic tool for the simultaneous differentiation of canid trichuroids (Di Cesare and Traversa, unpublished).

In conclusion, the guard against these three trichuroids affecting dogs should be kept high and they should always be included in the differential diagnosis of intestinal and respiratory diseases of companion animals. Veterinarians, parasitologists and laboratory technicians should be aware of their occurrence and always perform a thorough microscopic analysis of all trichuroid ova present in microscopic fields when examining any faecal sample collected from a dog.

\section{Competing interests}

The authors declare that they have no competing interests.

\section{Authors' contributions}

ADC: contributed in laboratory examinations and morphological and morphometric tests, interpretation of data and drafted the manuscript. GC: participated in morphological and morphometric tests and image analysis and elaboration. SM: examined the dog, collected the sample and performed morphological and morphometric analysis. DO: participated in analysis and interpretation of data and thoroughly commented on the manuscript. DT: participated in analysis and interpretation of data, and conceived and edited the manuscript. All authors reviewed and approved the manuscript.

\section{Author details}

${ }^{1}$ Department of Comparative Biomedical Sciences, University of Teramo, Valenzano, Italy. ${ }^{2}$ Department of Public Health and Zootechny, University of Bari, Valenzano, Bari, Italy.
Received: 14 April 2012 Accepted: 25 June 2012

Published: 25 June 2012

\section{References}

1. Traversa D: Are we paying too much attention to cardio-pulmonary nematodes and neglecting old-fashioned worms like Trichuris vulpis? Parasit Vectors 2011, 8:4-32.

2. Taylor MA, Coop RL, Wall RL: Veterinary Parasitology. 3rd edition. Oxford, UK: Blackwell Publishing; 2007.

3. Lalosević D, Lalosević V, Klem I, Stanojev-Jovanović D, Pozio E: Pulmonary capillariasis miming bronchial carcinoma. AmJTrop Med Hyg 2008, 78:1416.

4. Traversa D, Di Cesare A, Conboy G: Canine and feline cardiopulmonary parasitic nematodes in Europe: emerging and underestimated. Parasit Vectors 2010, 23:3-62.

5. Traversa D, Di Cesare A, Lia RP, Castagna G, Meloni S, Heine J, Strube K, Milillo P, Otranto D, Meckes O, Schaper R: New insights into morphological and biological features of Capillaria aerophila (Trichocephalida, Trichuridae). Parasitol Res 2011, 109(Suppl 1):S97-S104.

6. Conboy GA: Helminth parasites of the canine and feline respiratory tract. Vet Clin N Am Small Anim Pract 2009, 39:1109-1126.

7. Gajewska A, Gorski P, Kotomski G, Bogdanowicz M, Klockiewicz M, Kazimierczak K: Changes in parasites of dogs and cats from Warsaw and suburbs during the period of 1974-2002. Part III. Roundworms. Zycie Weterynaryjne 2004, 79:208-212. In Polish.

8. De Liberato C, Mazzanti S, Scaramozzino P: First report of Eucoleus bohmi (Nematoda Trichuridea) from Italy: parasitological findings and veterinary implications. Parassitologia 2009, 51:43-45.

9. Piperisova I, Neel JA, Tarigo J: What is your diagnosis? Nasal discharge from a dog. Vet Clin Pathol 2010, 39:121-122.

10. Baan M, Kidder AC, Johnson SE, Sherding RG: Rhinoscopic Diagnosis of Eucoleus boehmi Infection in a Dog. J Am Anim Hosp Assoc 2011, 47:60-63.

11. Traversa D, Di Cesare A, Milillo P, Iorio R, Otranto D: Infection by Eucoleus aerophilus in dogs and cats: is another extra-intestinal parasitic nematode of pets emerging in Italy? Res Vet Sci 2009, 87(2):270-272.

12. Evinger JV, Kazacos KR, Cantwell HD: Ivermectin for treatment of nasal capillariasis in dog. J Am Vet Med Assoc 1985, 186:174-175.

13. Campbell BG, Little MB: Identification of eggs of a nematode (Eucoleus boehmi) from the nasal mucosa of North American dogs. J Am Vet Med Assoc 1991, 54:145-154. 
14. Sloss MW, Kemp RL, Zajac AM: Veterinary Clinical Parasitology. Ames, IA: lowa State University Press; 1994.

15. Di Cesare A, Castagna G, Meloni S, Milillo P, Latrofa MS, Otranto D, Traversa $D$ : Canine and feline infections by cardiopulmonary nematodes in central and southern Italy. Parasitol Res 2011, 109(Suppl 1):S87-S96.

16. Di Cesare A, Castagna G, Otranto D, Meloni S, Milillo P, Latrofa MS, Paoletti B, Bartolini R, Traversa D: Molecular diagnosis of Capillaria aerophila, an agent of canine and feline pulmonary capillariosis. J Clin Microbiol 2012, 50:1958-1963.

doi:10.1186/1756-3305-5-128

Cite this article as: Di Cesare et al:: Mixed trichuroid infestation in a dog from Italy. Parasites \& Vectors 2012 5:128.

\section{Submit your next manuscript to BioMed Central and take full advantage of:}

- Convenient online submission

- Thorough peer review

- No space constraints or color figure charges

- Immediate publication on acceptance

- Inclusion in PubMed, CAS, Scopus and Google Scholar

- Research which is freely available for redistribution 